\title{
Turbulent characteristics of a semiarid atmospheric surface layer from cup anemometers - effects of soil tillage treatment (Northern Spain)
}

\author{
S. Yahaya, J. P. Frangi, and D. C. Richard \\ Laboratoire Environnement and Développement, CP 7071 Université Denis Diderot (Paris 7), 2 Place Jussieu, 75251 Paris \\ Cedex 05, France
}

Received: 13 May 2002 - Revised: 9 February 2003 - Accepted: 19 March 2003

\begin{abstract}
This paper deals with the characteristics of turbulent flow over two agricultural plots with various tillage treatments in a fallow, semiarid area (Central Aragon, Spain). The main dynamic characteristics of the Atmospheric Surface Layer (ASL) measured over the experimental site (friction velocity, roughness length, etc.), and energy budget, have been presented previously (Frangi and Richard, 2000). The current study is based on experimental measurements performed with cup anemometers located in the vicinity of the ground at 5 different levels (from 0.25 to $4 \mathrm{~m}$ ) and sampled at $1 \mathrm{~Hz}$. It reveals that the horizontal wind variance, the Eulerian integral scales, the frequency range of turbulence and the turbulent kinetic energy dissipation rate are affected by the surface roughness. In the vicinity of the ground surface, the horizontal wind variance logarithmically increases with height, directly in relation to the friction velocity and the roughness length scale. It was found that the time integral scale (and subsequently the length integral scale) increased with the surface roughness and decreased with the anemometer height. These variations imply some shifts in the meteorological spectral gap and some variations of the spectral peak length scale. The turbulent energy dissipation rate, affected by the soil roughness, shows a z-less stratification behaviour under stable conditions. In addition to the characterization of the studied ASL, this paper intends to show which turbulence characteristics, and under what conditions, are accessible through the cup anemometer.
\end{abstract}

Key words. Meteorology and atmospheric dynamics (climatology, turbulence, instruments and techniques)

\section{Introduction}

WELSONS (Wind Erosion and Losses of Soil Nutrients in semiarid Spain) is a European research project devoted to the study of desertification and land degradation by wind erosion in the European Mediterranean area. The main objective of

Correspondence to: J. P. Frangi (frangi@ccr.jussieu.fr) this project is to provide a better understanding of the impacts of climate and land-use changes on soil degradation by wind erosion for agricultural soils in the semiarid region of Northern Spain (Central Aragon, Spain, 1996-1998). Owing to theoretical considerations, micrometeorological parameters, such as the friction velocity, the roughness length and the evaporation, are very useful parameters to quantify wind erosion (e.g. Fryrear and Saleh, 1993; Gillette et al., 1974; Marticorena and Bergametti, 1995; Quiroga et al., 1998; Zobeck, 1991). The first two considerations allow for a description of the wind profile, and ultimately the prediction of wind erosion. Fallowing, in the traditional cereal-fallow rotation in this region, may enhance wind erosion hazard because of insufficient residues on the soil surface and the highly pulverised soils behind multiple tillage operations (during the fallow period, the soil is bare).

In order to study land-use effect on wind erosion, two adjacent plots were delimited in the experimental field for application of two kinds of tillage (conventional $\mathrm{CT}$ and Reduced RT, cf. Sect. 2). In a former paper, Frangi and Richard (2000) have already presented some results regarding the dynamics of the atmospheric surface layer (ASL) and the energy budget. After determining the main ASL parameters (friction velocity, roughness length, temperature scale, MoninObukhov length scale, etc.), it was pointed out that the two tillage methods induced differences in both dynamics characteristics and energy budget breakthrough between the two plots. All these results were obtained through the use of a mean wind profile.

As a continuation of that first work, the present study relies on the use of meteorological stations set up on each plot. The stations measure the wind speed profile, with five anemometers located at different levels and having a sampling frequency of $1 \mathrm{~Hz}$. The paper is organised in two parts. In the first part the characteristics of the experimental site and the main data related to the sensors, especially the anemometers, are presented. Some indications are also given on the experimental protocol and on the general data treatment methodology. The second part relates to the experimental results. We 


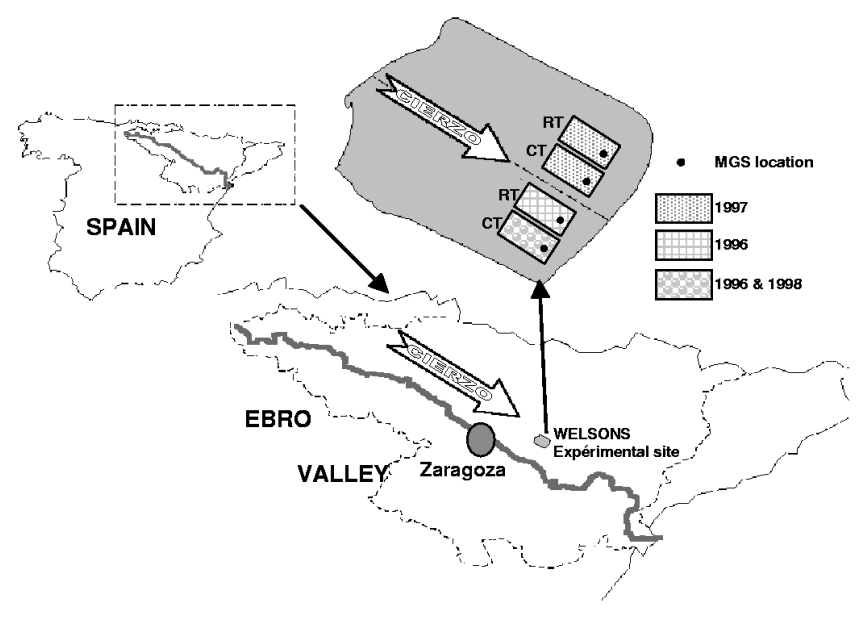

Fig. 1. General fetch of the WELSONS experimental site. One can notice the location of the conventional tillage (CT) and reduced tillage (RT) plots, changing according to years and the main wind direction following the Ebro Valley.

first present an investigation on the variance profile of the horizontal wind in the vicinity of the ground. The study has led to link this profile with some terrain characteristics, particularly the friction velocity and the roughness length. Then, some studies regarding the influence of the terrain roughness on the horizontal wind integral scales are presented. Spatial correlation between the two stations is also examined. Finally, the last part based on spectral analysis, reports some results related to the meteorological spectral gap, the spectral energy containing-scale, and the TKE dissipation rate.

\section{Experiment}

For a complete description of the WELSONS experiment, with a detailed description of the site, one should refer to Frangi and Richard (2000). The climate of this Spanish region is strongly influenced by two winds, namely Cierzo and Borchono, which are bound to a specific orography. In fact, the channel formed by the Cantabrico Cordillera to the northwest, the Pyrénéees Mountains to the north and the Iberian Cordillera to the south of the Ebro River, funnels each air flow, resulting in the main wind directions of WNW and ESE. The Cierzo is the wind from the WNW direction, a very cold air stream in winter and cool in summer. Two main meteorological situations can explain its appearance. The first is an anticyclone over the Cantabrico Sea and a lowpressure system above the Mediterranean Sea; the second is a strong low-pressure system to the north of Europe, coupled with a high-pressure area over the Azores. The first situation generates dry (from the foehn effect, see Schneider, 1996), strong and continuous winds. Cierzo events with gusts over $30 \mathrm{~m} . \mathrm{s}^{-1}$ are common in this region, especially during the summer (Biel and Garcia de Pedraza, 1962), and according to Skidmore (1965), erosive winds are those exceeding 5.3 $\mathrm{m} . \mathrm{s}^{-1}$ at $2 \mathrm{~m}$ height. In the second case, the air flow which blows over the whole of Europe has strong oceanic characteristics and causes wet weather with heavy swell conditions on the Atlantic coastline. In the opposite direction the Bochorno blows, with an ESE main direction, which appears when a pressure gradient exists between the Mediterranean Sea and the Cantabrico Sea, with a low pressure field over the latter. The Bochorno is generally a light wind (except in stormy conditions), and its direction is less well defined; it is temperate and moist in winter, and dry in summer, with a Saharan influence.

The traditional farming system of cereal-follow rotation extends over 250000 ha in Central Aragon (Lopez et al., 1996), and the soil during the fallow period is smooth and bare. The experimental field, located in an area called El Saso $\left(41^{\circ} 36^{\prime} \mathrm{N}, 0^{\circ} 32^{\prime} \mathrm{W}, 285 \mathrm{~m}\right.$ above mean sea level), $35 \mathrm{~km}$ away from Zaragoza in the Ebro Valley (Fig. 1), is oriented in the direction of the Cierzo prevailing wind (WNW). It remained untilled after a barley-fallow rotation. Fields surrounding it, in the upwind edge, had very sparse vegetation. On both sides, at a distance of about $200 \mathrm{~m}$, there were wheat fields, with a vegetation canopy lower than $30 \mathrm{~cm}$ and fallow fields of stubble separated the wheat fields from the experimental plots. The soil was a silt with $19.3 \%$ of sand, $67.6 \%$ of silt and $13.1 \%$ of clay (Gerakis and Baer, 1999) in the first $20 \mathrm{~cm}$. The experimental field was divided into two adjacent plots $\left(130 \times 160 \mathrm{~m}^{2}\right)$ for the application of two tillage treatments with a $20 \mathrm{~m}$ separation distance: conventional tillage (CT) and reduced tillage (RT). The CT treatment consisted of mould-board ploughing, at a depth of $30-35 \mathrm{~cm}$, followed by the pass of a compacting roller to obtain a very flat ground: it constitutes the traditional practice in this area. The RT treatment, an alternative practice of conservation tillage (Lopez et al., 1996), consists of a unique pass of a chisel plough at a depth of about $15-20 \mathrm{~cm}$, yielding a ground with furrows. In both cases, the tillages were done in the WNW direction. So the soil was bare with very different surface conditions during the whole experiment.

Two micrometeorological ground station (MGS) systems (Frangi and Richard, 2000) have been developed and set up on the experimental field to study the dynamical characteristics of the soil surface and the energy budget partitioning on both plots. They were installed in the downwind edge of the field to avoid a fetch effect. The devices measure the energy budget parameters: wind speed and direction, air temperature and vapour pressure at two levels, net radiation and ground heat flux, soil and surface temperature, and atmospheric pressure. In addition, they record the wind profile every one second, through a set of 5 cup anemometers installed along a $4 \mathrm{~m}$ height vertical mast, in order to determine the roughness length and the friction velocity during wind erosion events (Frangi and Poullain, 1997). The five anemometer heights are 28, 53,118, 203 and $402 \mathrm{~cm}$. The two MGS are synchronized. The 1997 WELSONS experiment was conducted from 29 June to 25 September.

Some concerns could arise about the inertial effects of the cup anemometers and regarding the low sampling rate of $1 \mathrm{~Hz}$. Given the anemometers' distance constants $(L \approx$ 


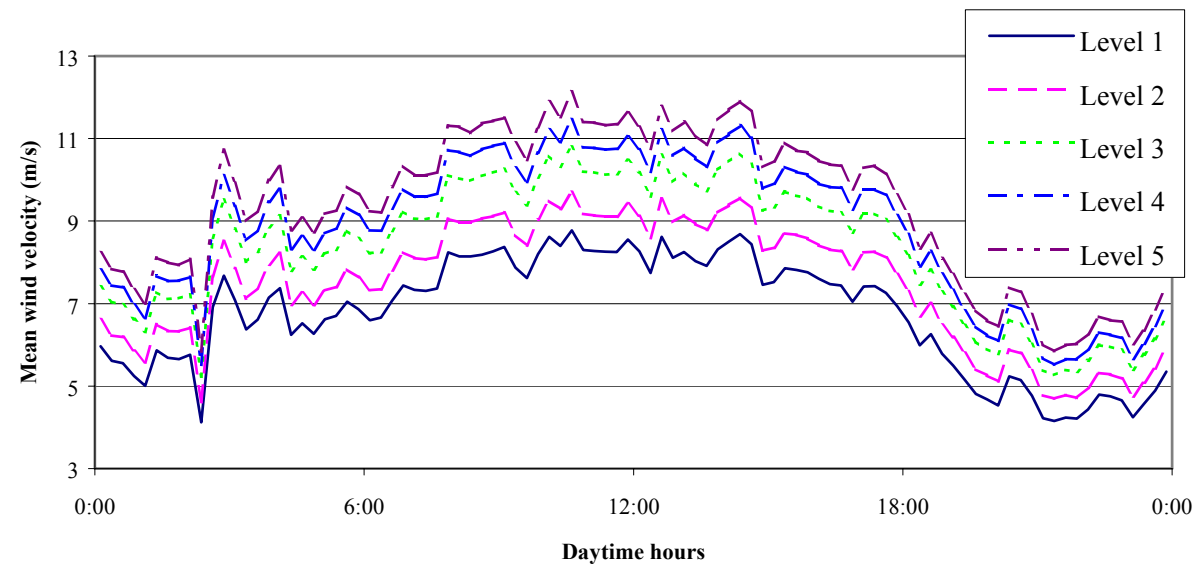

Fig. 2. Variation of the mean wind velocity during the day of 25 July 1997 at different levels.
$1.3 \mathrm{~m}$ ), the variance reduction due to the inertial effects was estimated to range from 0.6 to $1.5 \%$, respectively, for the top and bottom levels. In order to assess the magnitude of variance losses deriving from an insufficient sampling frequency, a complementary study was carried out, in an urban area, at University D. Diderot (Paris 7), with a three-dimensional sonic anemometer (Campbell CSAT3). Thus, a variance drop of about $10 \%$ was found between samplings of 1 and $32 \mathrm{~Hz}$, for wind velocity around $4 \mathrm{~m} \cdot \mathrm{s}^{-1}$, with turbulence intensity of about $40 \%$. In addition, the accordance found between the experimental and the von Karman spectra, notably in the upper frequency part (see Sect. 3.3.2), reinforces credit to the quality of the data.

Data concerning the wind velocity fluctuations are systematically detrended, except for the study of the spectral gap. In this case, the data corresponding to time intervals longer than $8 \mathrm{~h}$ are averaged over 2 or $3 \mathrm{~s}$. The mean wind velocity at the highest level of plot CT is around $11 \mathrm{~m} \cdot \mathrm{s}^{-1}$ during the daytime of 25 July 1997 and the turbulence intensity confined between $12 \%$ and $16 \%$ throughout the same day at the same level.

\section{Results}

3.1 Profile of the variance of the horizontal wind components in the ASL

The wind velocity variance, which represents the turbulent kinetic energy, is an important parameter of the ASL, since it conditions many phenomena taking place in this layer, such as the diffusion of chemical and physical aerosols, energy transfer between the mean and the turbulent flows, heat and mass transfer, extreme wind force exercised on structures, etc.

The wind data logged during the WELSONS experiment concern the bottom part of the ASL, since the lowest anemometer is located at $0.25 \mathrm{~m}$ from the ground, while the highest one is at $4 \mathrm{~m}$ (thus covering a height scale ratio of 16). This particularity of the experiment, due to its specific objectives, is expected to produce somewhat different results from common micrometeorological experiments.

\subsubsection{Variance of the horizontal wind components in the ASL}

Despite the existence of long established relationships (Panofsky et al., 1977), the behaviour of the variance of the horizontal wind components in the ASL is still discussed, especially the definition of their pertinent scaling parameters.

Thus, for Kaimal and Finnigan (1994), the horizontal wind components, contrary to the vertical one, are not governed by the Monin-Obukhov ASL similarity theory, which states that various atmospheric parameters and statistics, such as gradients, variances and co-variances, when normalized by appropriate powers of the scaling velocity $U *$ and the scaling temperature $\theta *$, become universal functions of the stability parameter. This is because the wind horizontal components do not depend on the height throughout the surface layer and most of the ABL, even in highly unstable conditions (Garrat, 1992). This property could be explained by the influence of low-frequency eddies, either through boundary-layer instabilities or convection, which makes the ABL depth, $Z_{h}$, the scaling height. Thus, in unstable conditions, Panofsky et al. (1977), proposed the following relationship:

$\frac{\sigma_{u}}{U *} \approx \frac{\sigma_{\nu}}{U *}=\left(12-0.5 \frac{Z_{i}}{L}\right)^{1 / 3}$,

where $Z_{i}$ is the daytime ABL depth. The establishment of this relationship relied on data obtained, on the one hand, from a mast up to $32 \mathrm{~m}$ and, on the other hand, from a tethered balloon for upper heights. Most of the data were obtained over water. No clear indications were available on the lowest measurement height, but a set of data from a 4-m height level is included.

In a recent study carried out by Hedde and Durand (1994) over the Mediterranean Sea, for heights between 30 and $50 \mathrm{~m}$ and for wind velocity between 6 and $20 \mathrm{~m} / \mathrm{s}$, it was shown 
Table 1. Variances of the horizontal wind components in neutral and stable conditions in the ASL, according to authors

\begin{tabular}{lllccc}
\hline \multirow{2}{*}{ Atmospheric conditions } & Authors & Specific conditions & $\frac{\sigma_{u}^{2}}{U_{*}^{2}}$ & $\frac{\sigma_{v}^{2}}{U_{*}^{2}}$ & $\frac{\sigma_{u}^{2}+\sigma_{v}^{2}}{U_{*}^{2}}$ \\
\hline Neutral & Raupach et al. (1990) & Flat terrain & 5.76 & 3.61 \\
& & Rolling terrain & 11.56 & 8.41 \\
& Hedde and Durand (1994) & Over sea & 4.00 & 1.69 & 8.5 \\
& Stull (1988) & & 6.1 to 6.5 & 2.9 to 6.1 & \\
& Solari (1987) & $Z_{0}<0.03 \mathrm{~m}$ & 7.5 & & \\
\hline Stable & Moraes and Epstein (1987) & & 4.71 & 3.17 & 8.5 \\
& Stull (1988) & & - & - & 16 \\
\hline
\end{tabular}

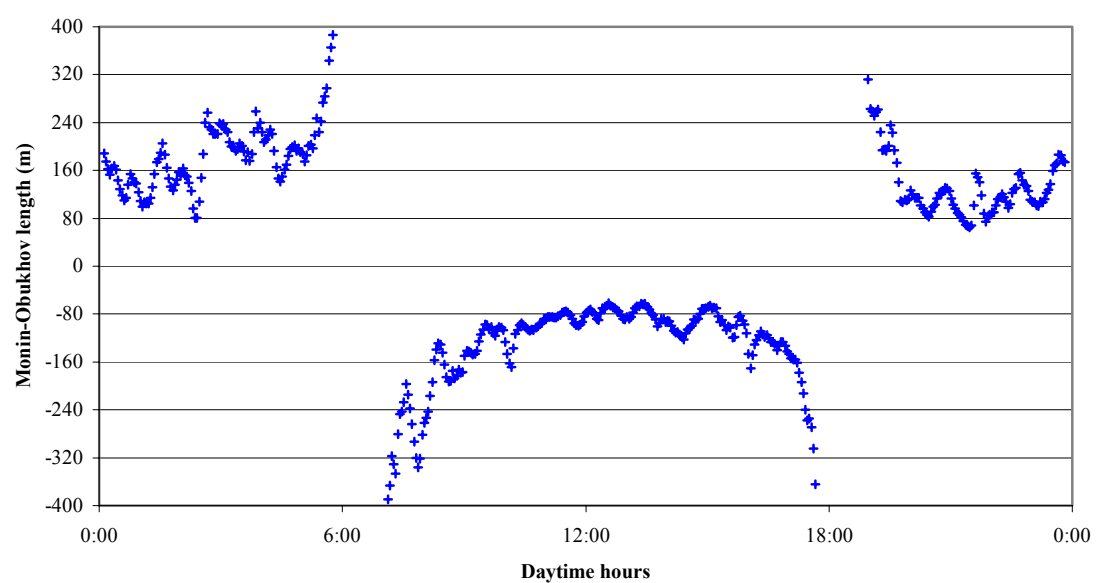

Fig. 3. Variation of the MoninObukhov length during the day of 25 July 1997 (Plot CT).

that the horizontal wind components followed the similarity theory yielding, for free convection:

$\frac{\sigma_{u}}{U *}=\frac{\sigma_{v}}{U *}=2.8\left(-\frac{z}{L}\right)^{1 / 3}$.

Saïd (1988) and Idé (1991) reported the same "1/3 law" with a constant of 2.0 and 5.4, respectively, instead of 2.8. Contrary to the other studies, the latter was carried out over land, in the semiarid Sahel region of Africa.

In stable conditions, Pahlow et al. (2001), analysing data from a set of five experiments, distinguished between two cases according to the stability parameter. The five experiments were carried out in the ASL at heights ranging from 0.96 to $4.32 \mathrm{~m}$. In weak stability conditions, i.e. when the stability parameter $\zeta \leq 0.1$, they observed that the normalized horizontal wind components adopted a local z-less stratification behaviour, becoming thus constant (Table 1). When the stability parameter exceeds this value, they proposed the following equation:

$$
\frac{\sigma_{\alpha}}{U *}=a+b\left(\frac{z}{L}\right)^{c}
$$

where $\alpha$ represents $u$ and $v ; a, b$ and $c$ equal 2.3, 4.3, and 0.5, respectively, for the longitudinal component, and 2.0, 4.0 and 0.6 for the transversal wind.
However, many authors indicate that, under stable conditions and in the ASL, the variances of horizontal wind components are constant. Table 1 summarises the typical values encountered. The data of Moraes and Epstein (1987) are valid for heights up to $22.6 \mathrm{~m}$, while no specific conditions were given by Stull (1988).

According to the Monin-Obukhov similarity theory, when conditions approach neutrality, the variances of the horizontal wind components become constant (Garrat, 1992). Typical values of the constants are presented in Table 1. Thus, for the experimental data, the values are around 6 for common terrain. For rolling terrain, the variance increases up to 20 and decreases down to 6 over sea.

Solari (1987) proposed a relationship for turbulence in the near-neutral ASL in which $\beta_{u}$, the constant ratio between the variance of the longitudinal wind velocity $\sigma_{u}^{2}$ and the square of the friction velocity $U_{*}^{2}$, depends on the terrain roughness, $Z_{0}$, i.e.:

$\beta_{u}=\frac{\sigma_{u}^{2}}{U_{*}^{2}}=\left\{\begin{array}{cl}7.5 & \text { for } Z_{0} \leq 0.03 \\ 4.5-0.856 \ln \left(Z_{0}\right) & \text { for } 0.03 \leq Z_{0} \leq 1 \\ 4.5 & \text { for } \quad Z_{0} \geq 1,\end{array}\right.$

where $Z_{0}$ is expressed in meters.

The WELSONS experiment somewhat escapes to the above-mentioned scheme, since it took place in the very 
Table 2. Linear regression parameters of the function $\sigma^{2} / U_{*}^{2}=f(\ln (z))=a \ln (z)+b$

\begin{tabular}{ccccccc}
\hline & $R^{2}>0.90$ & \multicolumn{2}{c}{ Slope, $a$} & \multicolumn{2}{c}{ Intercept, $b$} & $-\ln \left(Z_{0}\right)$ \\
& (total of cases = 475) & average & $\begin{array}{c}\text { Variation } \\
\text { coefficient }\end{array}$ & Average & Variation \\
coefficient & \\
\hline Plot CT & $95 \%$ & 1.160 & $32 \%$ & 8.074 & $15 \%$ & 8.11 \\
Plot RT & $97 \%$ & 1.156 & $26 \%$ & 5.311 & $17 \%$ & 5.81 \\
\hline
\end{tabular}

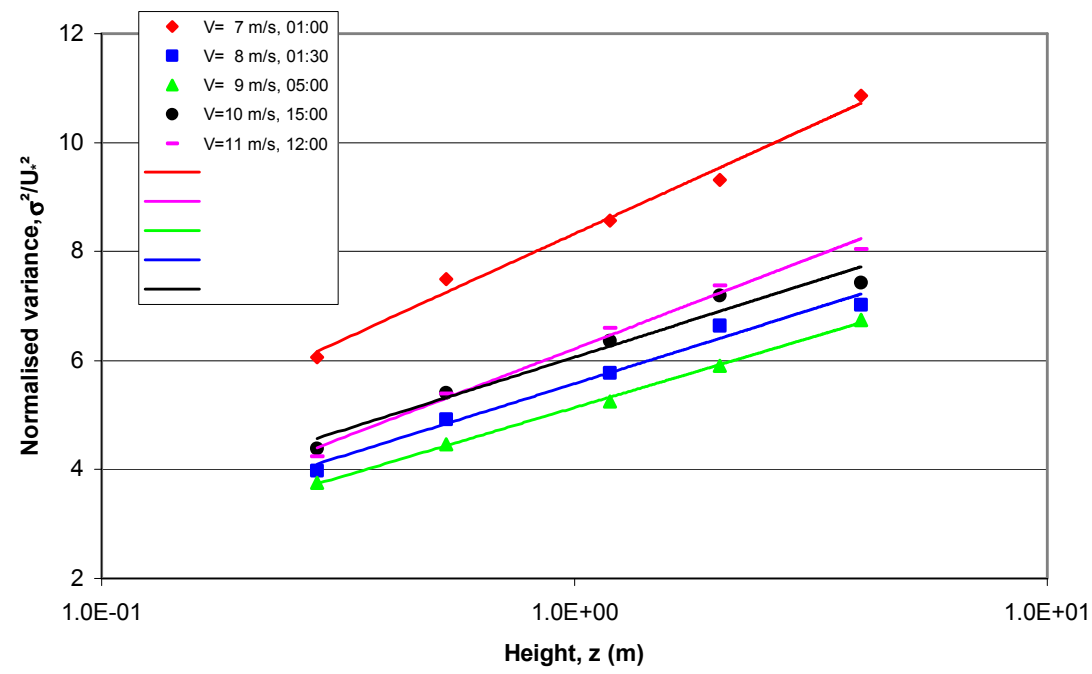

Fig. 4. Normalized variance $\left(\sigma_{u}^{2} / U_{*}^{2}\right)$ as a function of the height logarithm, $\ln (z)$, for various wind velocity (7 to $11 \mathrm{~m} / \mathrm{s})$ and at different daytime $(01: 00$ to 12:00 LT) (Plot RT, level 5, 25 July 1997).

vicinity of the ground. At these heights, the ground effects become important and thus, the roughness length becomes a relevant parameter, as it was in the case reported by Solari (1987). In addition, Hedde and Durand (1994) and Pahlow et al. (2001) reported that, in some circumstances, the variances of the horizontal wind components depend on the height. Besides any thermal stability considerations, the layer studied in the WELSONS experiment is rather a dynamic one, because the considered heights are negligible compared to the Monin-Obukhov length (Fig. 3) and the friction velocity is high (respectively, 0.4 and 0.5 in the two plots). These conditions of the dynamic layer occurrence were specified by De Moor (1983).

\subsubsection{Profile of the variance of the horizontal wind compo- nents in the WELSONS experiment}

The wind velocity data stemming from cup anemometers are the sums of the horizontal wind components. Since the study does not include the vertical wind component, we decided to linearly detrend the turbulent wind fluctuations in order to remove the mean flow influences. The variances are calculated over 14-min time intervals, to match with the data related to the friction velocity and the roughness length.

Figure 4 and Table 2 show that, in the specific experimental conditions, the horizontal wind variance normalized by the square of the friction velocity is a linear function of the logarithm of the height. In this analysis, the values of the friction velocity stem from previous published works (Frangi and Richard, 2000). In Table 2, we see that the linear correlation coefficient $R^{2}$ is higher than 0.9 in $95 \%$ of the 475 cases at plot CT and in $97 \%$ of the cases at plot RT. In light of this observation, it seems possible to model the normalized variance through the following relationship:

$\frac{\sigma^{2}}{U_{*}^{2}}=a \ln (z)+b$.

Table 2 gives the values of $a$ and $b$. We notice that the values of the constant $b$ (5.3 and 8.1, respectively, for the plots CT and RT), which represents the normalized variance at $1 \mathrm{~m}$, are of the same magnitude as those reported in Table 1. We also observe that the mean values of the constant $a$ are roughly the same in the two plots, while the opposite of the logarithms of the roughness lengths $Z_{0}$ are very close to the corresponding values of the constant $b$ (Table 2 ). This remark leads us to set $b=-\ln \left(Z_{0}\right)$ and thus, the relationship (5) becomes:

$\frac{\sigma^{2}}{U_{*}^{2}}=a \ln (z)-\ln \left(Z_{0}\right)$.

Using this equation and after adopting the empirical slope value $a=1.16$, we can generate the variance for every given anemometer height. Figure 5 compares the variance values 


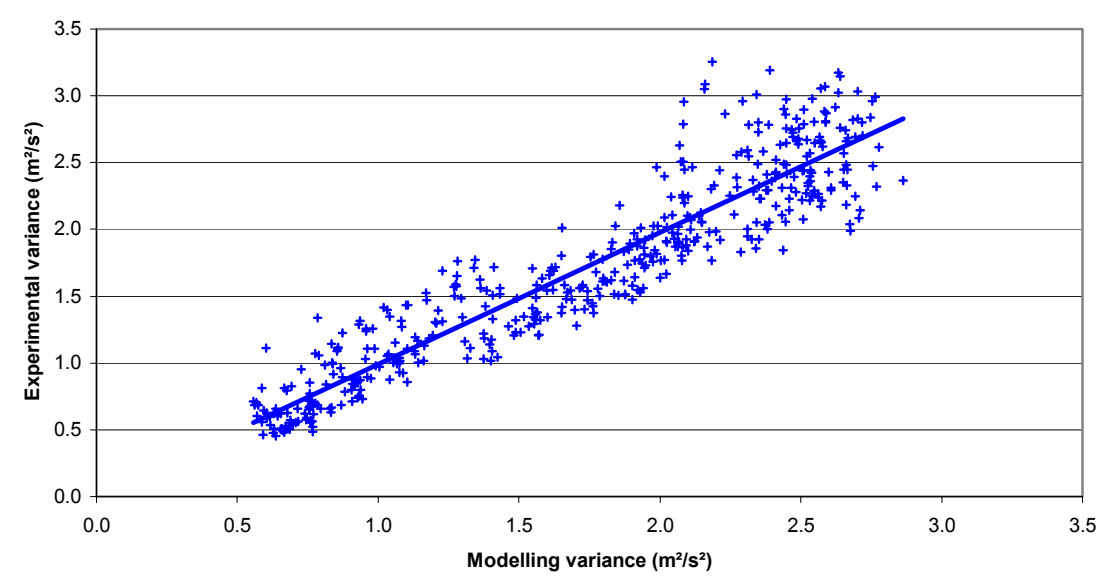

Fig. 5. Comparison between the experimental and the modelled data of the variance (plot CT, level 5, 25 July 1997), $y=0.9871 . x+0.0014, R^{2}=$ 0.8693 .
Table 3. Parameters of the linear regression between the modelling and the experimental data of the variance according to the anemometer levels

\begin{tabular}{ccccc}
\hline & & $\begin{array}{c}\text { Linear correlation } \\
\text { coefficient }\left(R^{2}\right)\end{array}$ & Slope, $a$ & Intercept, $b$ \\
\hline Plot CT & Level 1 & 0.90 & 0.97 & 0.06 \\
& Level 2 & 0.89 & 0.94 & 0.06 \\
& Level 3 & 0.87 & 0.95 & 0.04 \\
& Level 4 & 0.86 & 0.94 & 0.07 \\
& Level 5 & 0.87 & 0.99 & 0.00 \\
\hline Plot RT & Level 1 & 0.88 & 1.15 & 0.03 \\
& Level 2 & 0.87 & 1.06 & 0.06 \\
& Level 3 & 0.86 & 1.06 & 0.10 \\
& Level 4 & 0.85 & 0.99 & 0.17 \\
& Level 5 & 0.84 & 0.88 & 0.08 \\
\hline
\end{tabular}

coming from Eq. (6) to the experimental data. The friction velocity and the roughness length values are provided by Richard (2000). Table 3 gives the regression parameters between the modelled and the experimental data. Thus, we notice that the determination coefficient, the slope and the vertical intercept indicate good agreement between the two data sets.

In addition, Eq. (6) offer a prospective opportunity for the determination of the friction velocity and the roughness length from the variance profile. Figures 6 and 7 compare the values of the friction velocity and roughness length stemming from the variance and the mean wind velocity methods. The correlation between the values of the friction velocity is 0.86 and 0.87, respectively, in plots CT and RT (for the 475 data of 25 July 1997, over $24 \mathrm{~h}$ ). As far as the roughness length is concerned, which slightly varies, the correlation coefficient is nearly meaningless.
3.2 Temporal and spatial autocorrelation of the horizontal wind

Correlation parameters, notably the correlation function, the time and length integral scales, and the decay factors, are important for the understanding of the structure of the wind flow in the ASL and consequently, for the modelling of other parameters such as the wind spectrum. Such parameters are also required in the assessment of forces deriving from wind gust for the stability of structures (Schettini and Solari, 1998; Toriumi et al., 2000). Through the five anemometer levels and the two plots, we investigate the temporal and spatial (horizontally) correlation functions and their relating parameters, such as the time and length integral scales. As for the variance calculation, the wind velocity data are first linearly detrended within 15-min time interval samples.

The chart of the correlation function shows that, after a given time lag, the function begins oscillating within the value interval of $[-0.2 ;+0.2]$. This oscillation, which occurs after about ten seconds, can be explained as the influence of less rapid varying eddies. This kind of influence has been specified by Lumley and Panofsky (1964) in the calculation of the velocity variance.

The time integral scale, which is given by the integral of the correlation function, $\rho(t)$, between 0 and $\infty$, represents the time scale within which the considered turbulent parameter remains autocorrelated. For the experimental calculation of this scale, the correlation function $\rho$ is approximated by the elementary function:

$g(t)=b-a \ln (1+t)$,

where $t$ is the time (in second), and $a$ and $b$ are two constants. Although $b$ is very close to 1 , we did not fix it, in order to take into account the measurements' uncertainty. For the experimental calculation of the time integral scale, $g(t)$ offers two advantages compared to the well-known exponential equation:

$f(t)=\exp \left(-\frac{t}{T_{u}}\right)$ 

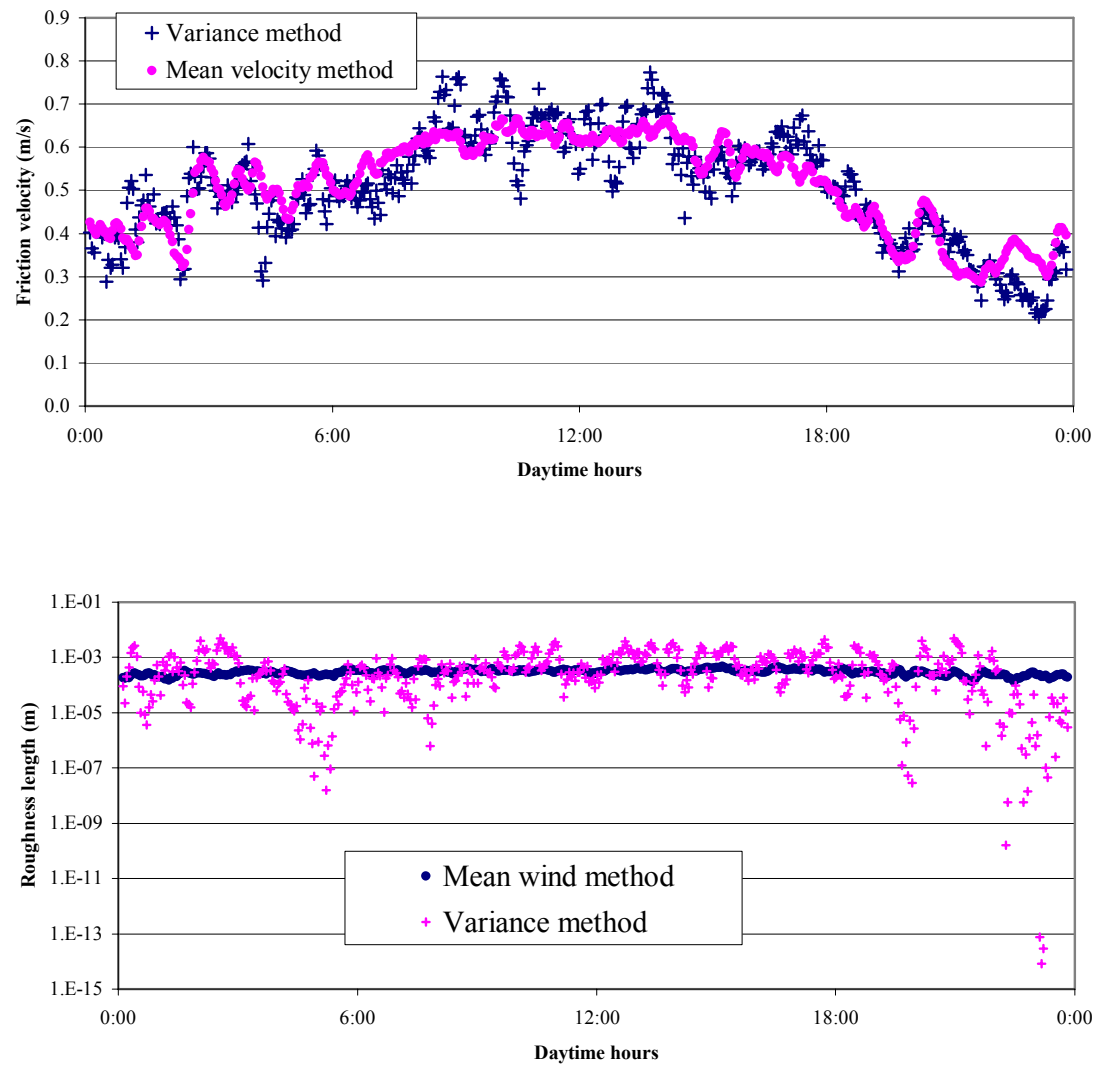

Fig. 6. Values of the friction velocities. Comparison between the variance (cross) and the mean wind methods (dot), plot RT, 25 July 1997. The mean wind method data are from Richard (2000).

Fig. 7. Values of the roughness length. Comparison between the variance (cross) and the mean wind methods (dot), plot CT, 25 July 1997. The mean wind method data are from Richard (2000). where $t$ is the time and $T_{u}$ is the time integral scale. On the one hand, $g(t)$ is expected to match with the first zero crossing value of the experimental correlation function and, on the other hand, it better correlates with the experimental data of the horizontal wind components. As suggested by Kaimal and Finningan (1994), the experimental computation of the time integral scale must take into account the first zero crossing value. This discussion does not mean that the theoretical exponential model of the correlation function is called into doubt.

Table 4 shows that the time integral scale is sensitive to the ground roughness and to the anemometer heights. In fact, it increases with the height and decreases with the roughness length. The ground vicinity, as well the terrain roughness, have, as particular effects, the disintegration of the eddies coherence.

The integral length scale, $L_{u}$, is obtained by multiplying the integral time scale by the mean wind velocity. This parameter, also called the Eulerian length integral scale, is a measure of the average spatial extent or coherence of the fluctuations. Table 4 gathers the mean values of the length integral scale at the different heights and plots. The data are averaged between 07:00 LT and 17:00 LT, when the mean wind velocity varies slightly.

As the integral length scale values range from 28 to $90 \mathrm{~m}$, no meaningful intercorrelation coefficient can be expected between the two stations distanced of $150 \mathrm{~m}$. Thus, it was found that the correlation coefficient between the two plots, ranges from -0.2 to 0.2 , even for the upper anemometer levels (4 and 5).

\subsection{Some spectral characteristics of the turbulent flow}

This section, which focuses on the spectral study of the turbulent flow, intends to show that the structure of the turbulent flow is modified by the terrain roughness. In addition, it reveals the spectral quality of the data measured by the cup anemometers.

3.3.1 The meteorological spectral gap and terrain roughness

The meteorological spectral gap is an important conceptual tool for the study of the turbulence. Application of the ergodic hypothesis principle leads to the estimation of the adequate averaging time $T$, assuming an acceptable error $\varepsilon$, as follows (Lumley and Panofsky, 1964):

$T=\frac{2 I_{f}}{\varepsilon^{2}} \frac{\overline{f^{\prime 2}}}{\overline{f^{2}}}$ with $\varepsilon=\frac{\sigma_{f}(T)}{\bar{f}}$,

where $\overline{f^{\prime 2}}$ is the ensemble variance of a stationary random function $f(t)$ about its ensemble mean $\bar{f}, I_{f}$ is the time integral scale and $\sigma_{f}(T)$ is the ensemble standard over the finite time $T$.

For the atmospheric flow, which is made up of a relatively rapidly varying quantity (turbulent flow) superimposed on a 
Table 4. Ratio of the spectral energy-containing scale to the length integral scale and the Von Karman spectrum's constant $c$, according to the plots and the anemometer levels. Average within the daytime interval 07:00-17:00 LT, 25 July 1997

\begin{tabular}{llccccc}
\hline & Anemometer levels & 1 & 2 & 3 & 4 & 5 \\
\hline \multirow{2}{*}{ Plot CT } & Mean time integral scale, $T_{u}(s)$ & 5.48 & 5.85 & 6.72 & 7.21 & 8.17 \\
& Time scale of the spectral peak, $T_{x}(s)$ & 24 & 29 & 40 & 43 & 48 \\
& Length scale of the spectral peak, $L_{x}(m)$ & 187 & 254 & 390 & 443 & 522 \\
& Length integral scale, $L_{u}(m)$ & 43.7 & 51.6 & 66.1 & 75.3 & 90.0 \\
& Ratio $L_{x} / L_{u}$ & 4.2 & 4.8 & 5.7 & 6.0 & 5.9 \\
& Constant $c$ & 2.59 & 2.92 & 3.50 & 3.65 & 3.61 \\
\hline \multirow{2}{*}{ Plot RT } & Mean time integral scale, $T_{u}(s)$ & 4.26 & 4.52 & 5.08 & 5.74 & 7.19 \\
& Time scale of the spectral peak, $T_{x}(s)$ & 14 & 17 & 28 & 35 & 42 \\
& Length scale of the spectral peak, $L_{x}(m)$ & 95 & 131 & 244 & 327 & 450 \\
& Length integral scale, $L_{u}(m)$ & 29.2 & 35.6 & 44.8 & 54.1 & 76.9 \\
& Ratio $L_{x} / L_{u}$ & 3.2 & 3.5 & 5.3 & 5.9 & 6.0 \\
& Constant $c$ & 1.97 & 2.17 & 3.27 & 3.60 & 3.65 \\
\hline
\end{tabular}

Table 5. Time period of the lowest value of the spectral gap according to the daytime period, the sample size and the experimental plot

\begin{tabular}{|c|c|c|c|c|c|}
\hline \multirow[t]{2}{*}{$\begin{array}{l}\text { Sample } \\
\text { Number }\end{array}$} & \multirow[t]{2}{*}{$\begin{array}{l}\text { Time Period of } \\
\text { the sample }\end{array}$} & \multirow[t]{2}{*}{$\begin{array}{c}\text { Sample } \\
\text { duration (hour) }\end{array}$} & \multicolumn{3}{|c|}{$\begin{array}{l}\text { Time period at the lowest } \\
\text { value of the gap (min) }\end{array}$} \\
\hline & & & Plot CT & Plot RT & $\begin{array}{l}\text { Difference between } \\
\text { Plots CT and RT }\end{array}$ \\
\hline 1 & 00:00-06:00 & 6 & 9.00 & 7.20 & 1.80 \\
\hline 2 & 03:00-09:00 & 6 & 12.00 & 8.57 & 3.43 \\
\hline 3 & $06: 00-12: 00$ & 6 & 21.18 & 21.18 & 0.00 \\
\hline 4 & 09:00-15:00 & 6 & 25.71 & 25.70 & 0.01 \\
\hline 5 & $12: 00-18: 00$ & 6 & 16.36 & 15.65 & 0.71 \\
\hline 6 & $15: 00-21: 00$ & 6 & 18.95 & 13.80 & 5.15 \\
\hline 7 & $18: 00-24: 00$ & 6 & 10.00 & 13.33 & -3.33 \\
\hline 8 & 00:00-08:00 & 8 & 9.06 & 7.87 & 1.19 \\
\hline 9 & 08:00-16:00 & 8 & 20.87 & 14.12 & 6.75 \\
\hline 10 & $16: 00-24: 00$ & 8 & 16.00 & 15.00 & 1.00 \\
\hline 11 & $00: 00-12: 00$ & 12 & 13.58 & 13.09 & 0.49 \\
\hline 12 & $12: 00-24: 00$ & 12 & 21.82 & 14.12 & 7.70 \\
\hline 13 & $00: 00-24: 00$ & 24 & 23.23 & 15.16 & 8.07 \\
\hline
\end{tabular}

slowly varying one (mean flow), the average value over a finite time approaches the value of the slowly varying component, and the variance of the average goes through a minimum given by (Lumley and Panofsky, 1964):

$\sigma^{2} \cong \frac{2 I_{1}}{T} \overline{f_{1}^{2}}+\frac{T^{4}}{24^{2}} \overline{f_{2}^{\prime \prime 2}}$

where the subscript 1 refers to the rapidly varying component and subscript 2 to the slowly varying one. The function $f_{2}^{\prime \prime}$ is a second derivative of $f_{2}$ and $I_{1}$ is the time integral scale. This relationship assumes that $T \gg I_{1}$ and yet is small enough to permit a local approximation of $f_{2}$ by parabolic arcs.
The optimum time that produces the minimum value of $\sigma^{2}$ can be obtained by differentiating Eq. (10), thus yielding:

$T_{0}=\left[288 I_{1} \frac{\overline{f_{1}^{2}}}{\overline{f_{2}^{\prime \prime 2}}}\right]^{1 / 5}$

and

$\sigma_{0}^{2}=\frac{5 I_{1}}{2 T_{0}} \overline{f_{1}^{2}}$.

By combining these two equations, we obtain the following expression:

$\sigma_{0}^{2}=\frac{5}{2(288)^{1 / 5}}\left(\overline{f_{1}^{2}}\right)^{4 / 5}\left(I_{1}^{4} \overline{f_{2}^{\prime \prime 2}}\right)^{1 / 5}$. 


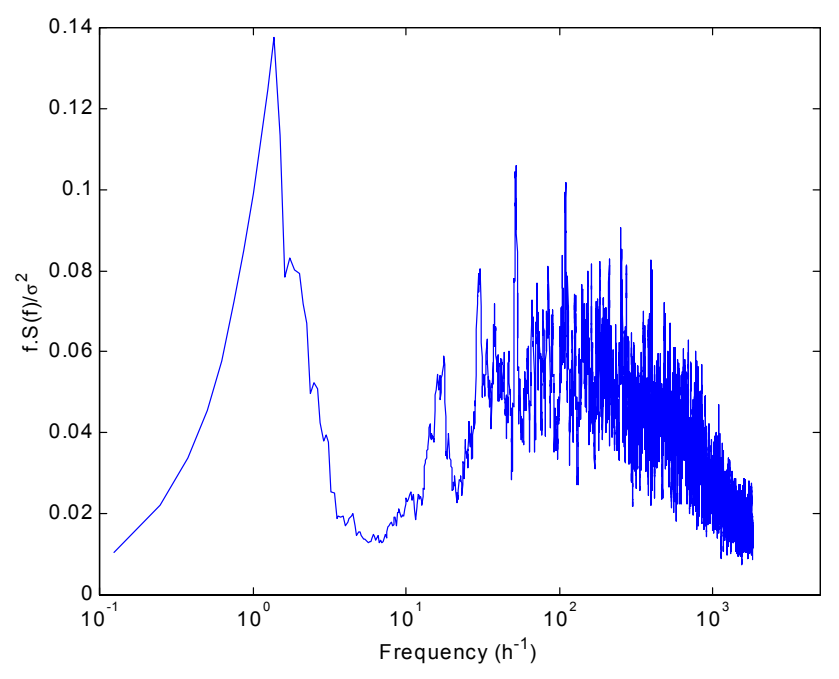

Fig. 8. Wind spectrum for the period 00:00-08:00 LT (Plot CT, 25 July 1997). One can see the spectral gap separating the mean and the turbulent flows.

If $f_{2}$ has a relatively sharp cutoff at the high-frequency end, then $\overline{f_{2}^{\prime \prime 2}}$ will be roughly proportional to the fourth power of the cutoff frequency. Thus, the above variance becomes proportional to the $4 / 5$ power of the ratio of the integral scale of the rapidly varying component to the smallest period of the slowly varying component.

The following investigation on the spectral gap uses the data obtained at $1-\mathrm{Hz}$ frequency on the top anemometer levels $(4 \mathrm{~m})$ of the two experimental plots. Samples, ranging from 6 to $24 \mathrm{~h}$ time intervals, are constituted of the data of 25 July 1997 (see Table 5). The Fourier transform is applied on the wind fluctuations after removing the mean velocity. Data are not detrended, in order to conserve a meaningful part of the mean flow. For the samples of 12 and $24 \mathrm{~h}$, the data have been, respectively, averaged over 2 and $3 \mathrm{~s}$.

The charts of the above-mentioned data reveal a middle frequency zone where the spectral energy is much lower than the two separated parts of the curves (Fig. 8). This spectral gap, pointed out by Van der Hoven (1957), is one of the characteristics of the wind flow in the ASL. Its constitutes one of the theoretical basis of the turbulent study techniques, since it provides a way to separate the turbulent flow from the influences of the mean flows (De Moor, 1983; Stull, 1988). In fact, the best method to separate the two scale flows consists of choosing the samples' time interval $T$, so that it falls into the gap zone. Thus, the spectral function of the "averaging operation" eliminates all the frequencies above $1 / T$, i.e. the turbulent frequencies.

In Table 5, we notice that the lowest amplitude of the spectral gap is located within the time period interval of 7 to $26 \mathrm{~min}$, depending on the daytime period and the sample size. This is in accordance with the values indicated by Van der Hoven, who locates the centres of the spectral gap within the time period interval of 6 to $60 \mathrm{~min}$.

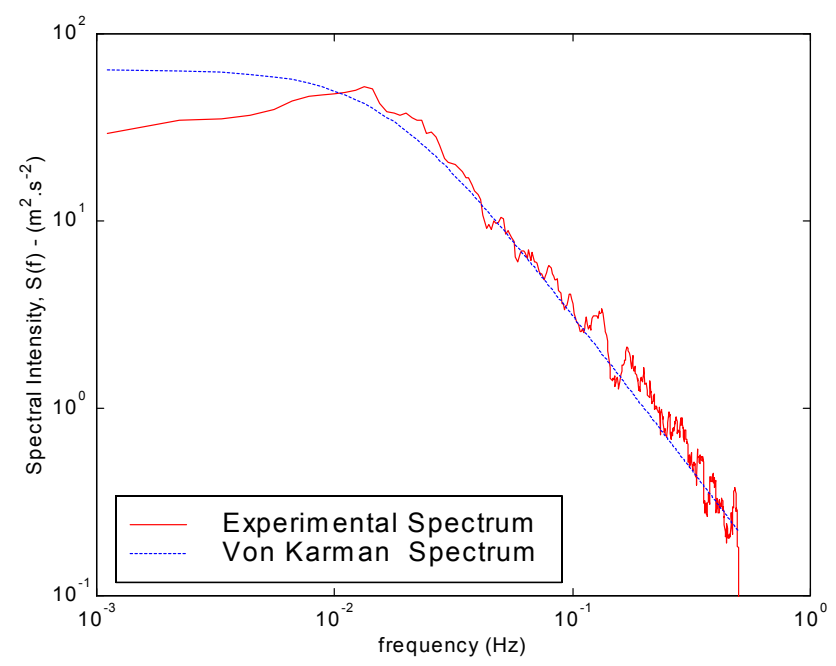

Fig. 9. Comparison between the experimental and the Von Karman wind spectra (Plot CT, level 5, 25 July 1997, 02:45-03:00 LT).

By comparing the gap range frequencies over the two plots, we observe a shift of the gap zone towards the higher frequencies, from the plot CT to the plot RT, in $85 \%$ of the 13 studied samples. This shift is conserved in length scales, since the mean wind velocity is higher in plot CT than in plot RT. The roughness lengths of the two WELSONS experimental plots are about 0.3 and $3 \mathrm{~mm}$ (respectively, for plot $\mathrm{CT}$ and RT). Moreover, Eq. (12) shows that the time integral scale can have some influences on the characteristics of the spectral gap and that the time integral scale depends on the terrain roughness (See Sect. 3.2). So, we can conclude that the terrain roughness pushes the turbulent frequency range towards higher frequencies.

\subsubsection{Some properties of the horizontal wind spectrum}

In this section we will validate the quality of the spectra stemming from the cup anemometer data and study the variation of scales corresponding to the turbulent spectral peaks (energy-containing scales), in relation to the ground surface roughness and the anemometer levels. The spectra of the wind velocity fluctuations are computed from samples with a 15 -min interval duration sampled at $1 \mathrm{~Hz}$. Before applying the Fourier transform, the data are first detrended. The study focuses on the time period 07:00-17:00 LT, which has stationary and high values of the mean wind velocity.

The obtained results are then compared with the Von Karman (1948) spectrum formula written as:

$S_{u}(f)=\frac{4 \cdot \sigma_{u}^{2} \cdot L_{u}}{U} \cdot\left[1+\left(\frac{2 \cdot c \cdot L_{u}}{U}\right)^{2} \cdot f^{2}\right]^{-5 / 6}$,

where $\sigma_{u}$ is the standard deviation of the horizontal wind, $L_{u}$ is length integral scale (see Sect. 3.2), $U$ is the mean velocity, and $c$ is a constant depending on the nature of the terrain. The value 4.207 is usually used for $c$ (Shiau, 2000; Lungu et al., 1996). 


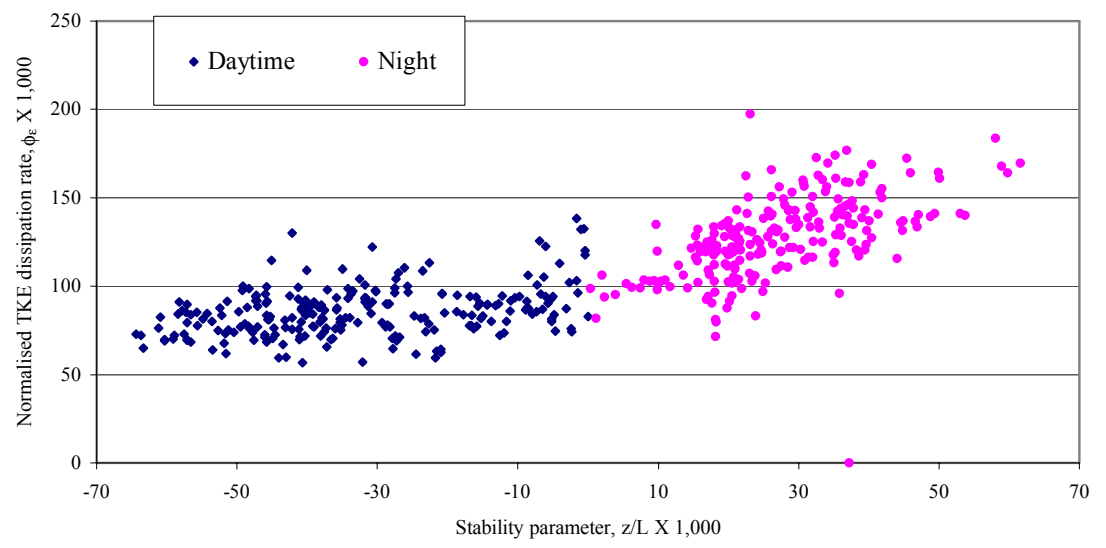

Fig. 10. Chart of the normalized TKE dissipation rate during daytime (diamond-shaped) and night (dot). Plot CT, level 5, 25 July 1997, through $24 \mathrm{~h}$.
Figure 9 presents a comparison between the experimental and the modelled nightly spectrum of the horizontal wind. The results are similar, indeed even better during than the daytime when the mean wind is higher. Thus, we conclude that the wind velocity fluctuation data furnished by the anemometers are good from a spectral point of view.

The chart in Fig. 9 uses log-log system axes. However, the spectra can also be charted in semilog axes, with $f . S_{u}(f)$ in the $y$-axis and $\ln (f)$ in the $x$-axis, which has the advantage of representing the energy of the corresponding frequency range by the area under the curve. In these axes, some characteristics regarding the spectral peak have been noticed. The time period $T_{x}$ of the spectral peak (and subsequently the corresponding length scale) increases with the anemometer height and decreases with the soil roughness (Table 4). The ratio of the time period between levels 1 and 5 is about 2 in plot $\mathrm{CT}$ and 4 in plot RT. This means that the rate also varies the roughness. This phenomenon of increasing length integral scale with heights can be explained by the large eddies damping in the vicinity of the ground.

In addition, a relationship between the spectral peak length scale and the length integral scale is reported in literature. Thus, Kaimal and Finnigan (1994) pointed out that the spectral peak length scale, $L_{x}$, was roughly 6 times the integral length scale, $L_{u}$, i.e.:

$L_{x} \approx 6.3 L_{u}$.

This relationship can also be retrieved, for example, from the Von Karman spectrum model (see Eq. 14), by solving the equation:

$\frac{d\left(f . S_{u}(f)\right)}{d(\ln (f))}=0$,

leading to:

$\frac{L_{x}}{L_{u}}=c \cdot \sqrt{\frac{8}{3}} \approx 1,63 c$,

where $c$ is the above-mentioned constant of Eq. (13).

In Table 4, we notice that the ratio of the spectral peak length scale to the length integral scale is roughly the same as that reported by Kaimal and Finnigan (1994), for the two top levels (4 and 5). The constant $c$ is of the same magnitude as that used in literature (3.60 versus 4.2). However, these parameters have to be adjusted for the lower levels (1 to 3). Thus, the length scales' ratio range from 3.2 to 5, meanwhile the constant $c$ varies from 2 to 3 . This suggests that the ratio, as well as the constant $c$, might depend on the height.

\subsubsection{The behaviour of the kinetic energy dissipation rate}

The dissipation rate of the turbulent kinetic energy is one of the components of the turbulent kinetic energy budget and one of the important non-dimensional forms to emerge in the ASL (Kaimal and Finnigan, 1994). Its behaviour in the ASL is still discussed in despite of many long established models. Its non-dimensional form, $\Phi_{\varepsilon}$, is assumed to follow the Monin-Obukhov similarity and thus, can be expressed as a function of the stability parameter, $z / L$, i.e.:

$\phi_{\varepsilon}=\frac{k \cdot z \cdot \varepsilon}{U_{*}^{3}}=f\left(\frac{z}{L}\right)$,

where $k$ and $U_{*}$ are the Von Karman constant and the friction velocity, respectively.

Thus, Kaimal and Finnigan, relying essentially on the Kansas results (Businger et al., 1971; Wyngaard and Coté, 1971), re-examined and refined through comparison with other observations (Dyer, 1974; Högström, 1988), proposed the following relationships:

$\phi_{\varepsilon}=\left\{\begin{array}{cc}\left(1+0.5\left|\frac{z}{L}\right|^{2 / 3}\right)^{3 / 2} & -2 \leq \frac{z}{L} \leq 0 \\ 1+5 \frac{z}{L} & 0 \leq \frac{z}{L} \leq 1 .\end{array}\right.$

We notice that, although it is not explicitly stated, these relationships are not valid beneath a certain height, otherwise the energy dissipation rate $\varepsilon$ will tend to $\infty$ when $z$ tends to 0 . They also suggest that, in the nearly neutral conditions (i.e. $z / L \approx 0), \Phi_{\varepsilon}$ is equal to 1 , which means that the mechanical production term equals the dissipation one.

For stable conditions, the lower part of Eq. (18) can be rewritten as:

$\phi_{\varepsilon}=A+\gamma \frac{z}{L}$. 

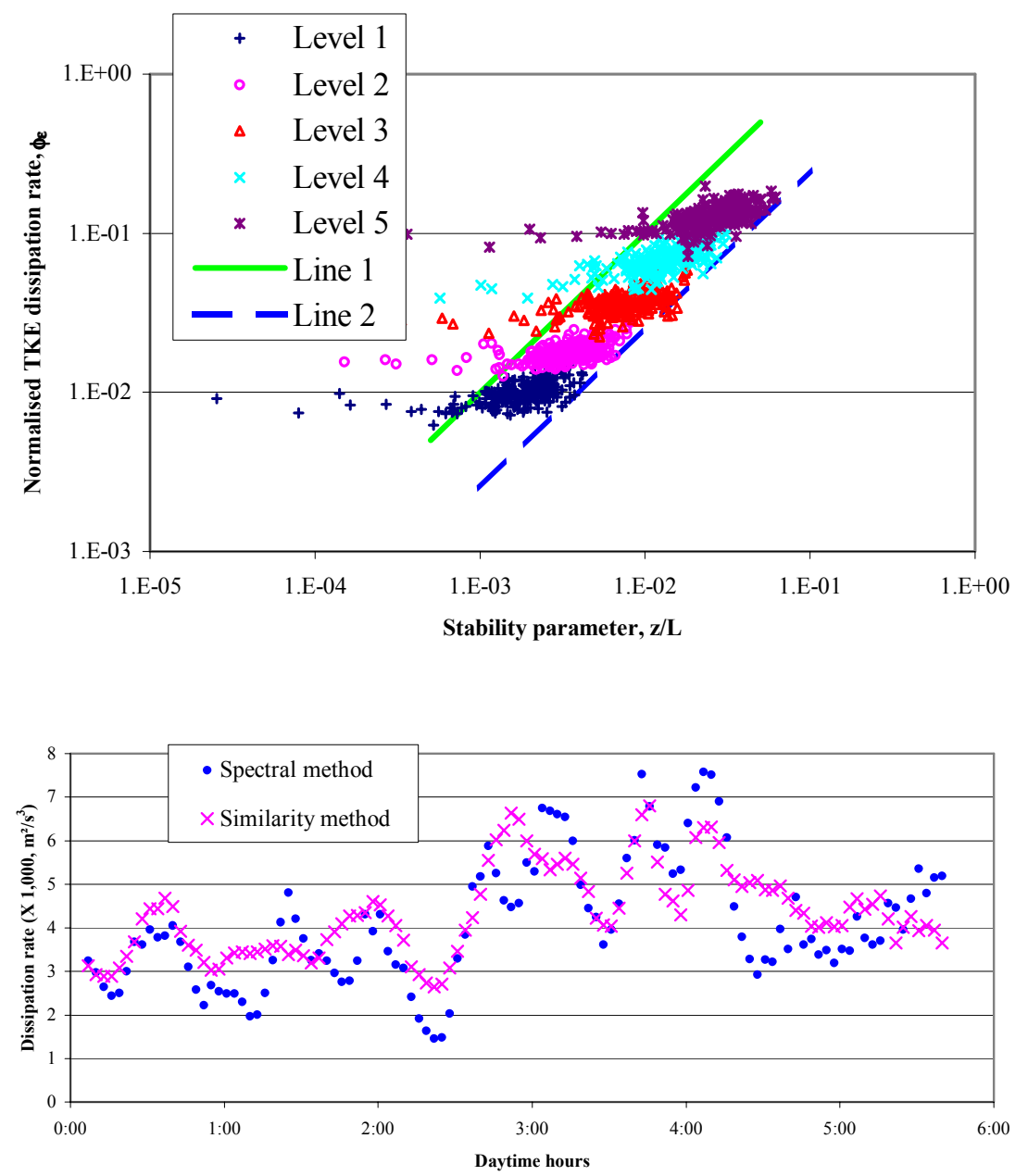

Fig. 11. Chart of the normalized TKE dissipation rate by night for the five levels on plot CT (25 July 1997), i.e. level 1 (cross), level 2 (circle), level 3 (triangle), level 4 (X), level 5 (star), solid and dash lines verifying equations $y=$ $\gamma(z / L)$.

Fig. 12. TKE dissipation rate. Comparison between the similarity (cross) and the spectral (dot) methods. Plot CT, level 5, 25 July 1997.
In a recent paper, Pahlow et al. (2001) found that, in strong stability conditions, the function of the TKE dissipation rate was better described when the constant $A$ equals 0.61 , confirming another result reported by Abertson et al. (1997). A summary of the experimental conditions of Pahlow et al. is already reported in Sect. 3.1.1. Furthering this result, Pahlow et al., relying on the behaviour of the heat flux in very strong stability, show that, for this limit, $A$ becomes very small compared to $\gamma(z / L)$ and thus yielding:

$\phi_{\varepsilon}=\frac{k \cdot z \cdot \varepsilon}{U_{*}^{3}}=\gamma \frac{z}{L}$

and

$\frac{k L \varepsilon}{U_{*}^{3}}=\gamma$.

They reported a constant $\gamma$ equal to 5 . The same relationship was proposed by Stull (1988), for the stable ASL but with $\gamma=3.7$. In these conditions, the TKE dissipation rate obeys the concept of z-less stratification.

As underlined above, in the vicinity of the ground, Eq. (18) cannot describe the behaviour of the TKE dissipation rate. In these conditions, the z-less stratification law can be investigated. According to the similarity theory, the spectral density of the wind velocity, in the inertial sub-range $S_{u}(k)$ is related to the kinetic energy dissipation $\varepsilon$ by the equation:

$S_{u}(\kappa)=\alpha_{K} \varepsilon^{2 / 3} \kappa^{-5 / 3}$,

where $\kappa$ is the wave number and $\alpha_{K}$ the double of the onedimensional Kolmogorov constant taken to be 0.55 , in accordance with Kaimal and Finningan (1994), who suggest the interval $[0.5-0.6]$. It appears that $\varepsilon$ is a function of the vertical intercept of the regression line: $\ln \left(S_{u}(\kappa)\right)=f(\ln (\kappa))$. Thus, we can calculate the dissipation rate by locating the inertial sub-range through the $-5 / 3$ slope of the log-log spectrum chart.

Figure 10 shows the variation of the normalised TKE dissipation rate during 25 July 1997, at level 5 of Plot CT. One can see that the rate increases faster during the night than during the daytime with the stability parameter. By charting the values of the TKE dissipation rate, during night, for the five anemometer levels, we notice that all the data are concentrated between two lines, $D_{1}$ and $D_{2}$, verifying Eq. (20a), (see Fig. 11). This observation leads us to express the TKE dissipation rate in the form of this equation.

In Fig. 12 one can notice that the dissipation rate calculated with the spectral method is comparable with the data 
stemming from Eq. (20b), by using the Monin-Obukhov length scale and the friction velocity determined by Richard (2000). Concerning the constant $\gamma$, the value 6 fits well in both plots CT and RT. This value is higher than that of 3.7 suggested by Stull (1988), but very to close the one reported by Pahlow et al. (2001), which is 5. The correlation coefficient between the two data sets of the TKE dissipation rate is 0.79 in plot CT and 0.55 in plot RT.

This observation suggests that, in the vicinity of the ground, when the ground is colder than the air (a difference of about $2^{\circ} \mathrm{C}$ in this case), the TKE dissipation rate can adopt the z-less stratification behaviour. Regarding the TKE dissipation rate under unstable conditions (during daytime), no clear specific behaviour has been noticed.

\section{Conclusion}

The behaviour of some ASL parameters in the close vicinity of the ground and according to the terrain roughness variation was studied. Thus, this paper showed that the variance of the horizontal wind varies logarithmically with height. The parameters of the logarithmic function are closely related to the ASL parameters, particularly the friction velocity and the roughness length scale. These results could be used for accurate calculation of the wind velocity standard deviation and variance in models involving the two parameters, see Eq. (6).

We also showed that the Eulerian integral scales were sensitive to the surface roughness and to the anemometer heights. In fact, the scale increases with the first parameter and decreases with the second one. Given the relationship between the time integral scale and the meteorological spectral gap (see Eq. 12), it was found that an increase in the roughness implied a shift towards higher frequencies in the location of the gap. In addition, the spectral peak length scale, which is linked to the Eulerian length integral scale (see Eq. 14), increases with height and decreases with the roughness.

The study of the TKE dissipation rate led to the conclusion that the parameter presents a z-less stratification behaviour under stable conditions. The results could be used, for example, to determine the magnitude of the heat flux from the friction velocity and the TKE dissipation rate, the latter being accessible from a single anemometer data.

We showed that cup anemometers could be used to study some turbulence characteristics in the ASL, in particular, in severe conditions of sand storms, where other sensors are less effective. Furthermore, specific characteristics could be revealed through data stemming from a cup anemometer. However, further studies are necessary to border the experimental limits of the apparatus.

Finally, the soil tillage treatment seemed to affect the turbulent flow characteristics of the ASL. Thus, the tillage modifies the interface parameters between soil and atmosphere. This property could serve in many applications relating to soil erosion, agriculture, etc.

\section{Abbreviations and acronyms}

$\begin{array}{ll}\text { ABL } & \text { Atmospheric Boundary Layer } \\ \text { ASL } & \text { Atmospheric Surface Layer } \\ \text { CT } & \text { Conventional Tillage } \\ \text { ESE } & \text { East-South-East } \\ \text { MGS } & \text { Micrometeorological Ground Station } \\ \text { RT } & \text { Reduced Tillage } \\ \text { TKE } & \text { Turbulent kinetic energy } \\ \text { WELSONS } & \text { Wind Erosion and Losses of Soil Nutrients } \\ & \text { in semiarid Spain } \\ \text { WNW } & \text { West-North-West }\end{array}$

\section{List of Symbols}

a Constant, generally slopes of linear regressions

A Constant

$b$ Constant, generally the vertical intercept of linear regressions

c Constant

$f$ frequency, random function, function

$g$ function

$I_{f}$ Time integral scale of the random function $f$

$k$ Von Karman constant

$L \quad$ Monin-Obukhov length

$L_{u}$ Length integral scale

$L_{x}$ Spectral energy-containing scale

$S_{u}$ Spectral density function of $u$

$t$ time

$T$ averaging time interval

$T_{u}$ time integral scale

$u$ wind velocity

$U$ mean wind velocity

$U_{*}$ Friction velocity

$z$ Height

$Z_{0}$ roughness length

$Z_{i}$ daytime ABL depth

$\alpha_{K}$ Kolmogorov constant

$\beta_{u}$ Ratio between the variance of $u$ and the square of the friction velocity

$\gamma$ Constant

$\varepsilon \quad$ TKE dissipation rate, error

$\kappa$ Wave number

$\sigma \quad$ standard deviation of the horizontal wind velocity

$\zeta$ Stability parameter

$\sigma_{\alpha} \quad$ Standard deviation relating to $\alpha$

$\Phi_{\varepsilon}$ Normalized TKE dissipation rate

Acknowledgements. The European Commission-Environment and Climate Programme DG XII, which sponsored this work under contract $\mathrm{n}^{\circ}$ ENV4-CT95-0182; Reviewers for their detailed inspection of the paper.

Topical Editor J.-P. Duvel thanks two referees for their help in evaluating this paper. 


\section{References}

Albertson, J. D., Parlange, M. B., Kiely, G., and Eichinger, W. E.: The average dissipation rate of turbulent kinetic energy in the neutral and unstable atmospheric surface layer, J. Geophys. Res., 102, 13 423-13 432, 1997.

Biel, A. and Garcia de Pedraza, L.: El clima en Zaragoza y ensayo climatologico para el valle del Ebro, Ministerio del Aire, Servicio Meteorologico National, Publicaciones Ser. A (Memorias), 36, Madrid, 57 pp., 1962.

Businger, J. A., Wyngaard, J. C., Izumi, Y., and Bradley, E. F.: Flux profile relationships in the atmospheric surface layer, J. Atmos. Sci., 28, 181-189, 1971.

De Moor, G.: Les théories de la turbulence dans la couche limite atmosphérique, Direction de la Météorologie, 312 pp., 1983.

Dyer, A. J.: A review of flux-profile relations, Bound. Layer Meteorol., 1, 363-372, 1974.

Frangi, J. P. and Poullain, P.: Un système d'acquisition haute vitesse de données dynamiques, associé à une station de mesure du bilan d'énergie de surface, Sécheresse, 8, 70 p., 1997.

Frangi, J. P. and Richard, D. C.: The WELSONS experiment: overview and presentation of first results on the surface atmospheric boundary-layer in semiarid Spain, Ann. Geophysicae, 18, 365-384, 2000.

Fryrear, D. W. and Saleh, A.: Field wind erosion: vertical distribution, Soil Sci., 155, 294-300, 1993.

Garrat, J. R.: The atmospheric Boundary Layer, Cambridge Atmospheric and Space Science Series, 316 pp., 1992.

Gerakis, A. and Baer, B.: A computer program for soil textural classification, Soil Sci. Soc. Am. J., 63, 807-808, 1999.

Gillette, D. A., Blifford, I. H., and Fryrear, D. W.: The influence of wind velocity on size distribution of aerosols generated by the wind erosion of soils, J. Geophys. Res., 79, 4068-4075, 1974.

Hedde, T. and Durand, P.: Turbulence intensities and bulk coefficients in the surface layer above the sea, Bound.-Layer Meteorol., 71, 415-432, 1994.

Högström, U.: Non-dimensional wind and temperature profiles. Bound.-Layer Meteor., 42, 55-78, 1988.

Idé, H.: Dynamics and turbulence in the Sahelian surface atmospheric boundary layer (STARS experiment), in French, Thesis Nr 982, University Paul Sabatier, Toulouse, France, 228 pp., 1991.

Kaimal, J. C. and Finnigan, J. J.: Atmospheric Boundary Layer Flows, Their Structure and Measurement, Oxford University Press, 289 pp., Edition 1994.

Lopez, M. V., Arrue, J.-L., and Sanchez-Giron, V.: A comparison between seasonal changes in soil water storage and penetration resistance under conventional and conservation tillage systems in Aragon, Soil Tillage Res., 37, 251-271, 1996.

Lumley, J. L. and Panofsky, H. A.: The structure of atmospheric turbulence, Wiley-Interscience, New York, 239 pp., 1964.

Lungu, D., Van Gelder, P. H. A. J. M., and Trandafir, R.: Comparative study of Eurocode 1, ISO and ASCE procedures for calculating wind loads, International Association for Bridge and Structural Engineering (IABSE) Report. Vol. 74, pp. 345-354, Delft, March 1996.
Marticorena, B. and Bergametti, G.: Modeling the atmospheric dust cycle: 1. Design of a soil-derived dust emission scheme, J. Geophys. Res., 100, 16415-16430, 1995.

Monin, A. S. and Obukhov, A. M.: Basic laws of turbulent mixing in the ground layer of the atmosphere, Trans. Geophys. Inst. Akad. Nauk USSR, 151, 163-187, 1954.

Moraes, O. L. L. and Epstein, M.: The velocity spectra in the stable surface layer, Bound.-Layer Meteorol., 40, 407-414, 1987.

Pahlow, M., Parlange, M. B., and Porté-Agel, F.: On the MoninObukhov similarity in the stable atmospheric boundary layer, Bound.-Layer Meteorol., 99, 225-248, 2001.

Panofsky, H. A., Tennnekes, H., Lenschow, D. H., and Wyngaard, J. C.: The characteristics of turbulent velocity components in the surface layer under convective conditions, Bound.-Layer Meteorol., 11, 355-361, 1977.

Quiroga, A. R., Buschiazzo, D. E., and Peinemann, N.: Management discriminant properties in semiarid soils, Soil Sci., 163, 591-597, 1998.

Raupach, M. R., Antonia, R. A., and Rajagopalan, S.: Rough-wall turbulent boundary layers, Appl. Mech. Rev., 44, 1-25, 1990.

Richard, D. C.: Contribution to the study of the Spanish semi-arid ASL, within the framework of WELSONS Project, in French, Thesis $\mathrm{n}^{\circ}$ 2000PA077201, University Denis Diderot, Paris 7, France, 303 pp., 2000.

Saïd, F.: "Experimental study of the marine boundary layer: Turbulence structure and surface fluxes (TOSCANE-T Experiment)", in French, Thesis Nr 248, University Paul Sabatier, Toulouse, France, 335 pp., 1988.

Schettini, E. and Solari, G.: Probabilistic modeling of maximum wind pressure on structures, J. Wind Eng. Ind. Aerodyn., 74-76, 1111-1121, 1998.

Schneider S. H.: Encyclopdia of climate and weather, Oxford University Press (Pub), 929 pp., 1996.

Shiau, B.-S.: Velocity spectra and turbulence statistics at the northeastern coast of Taiwan under high-wind conditions, J. Wind Eng. Ind. Aerodyn., 88, 139-151, 2000.

Skidmore E. L.: Assessing wind erosion forces: directions and relative magnitudes, Soil Sci. Soc. Am. J. Proc., 29, 587-590, 1965.

Solari, G.: Turbulence modelling for gust loading, J. Struct. Engin, ASCE, 113, 7, 1150-1569, 1987.

Stull, R. B.: An Introduction to Boundary Layer Meteorology, Atmospheric Sciences Library, Kluwer Academic Publishers, 670 pp., 1988, Edition of 1999.

Toriumi, R., Katsuchi, H., and Furuya, N.: A study on spatial correlation of natural wind, J. Wind Eng. Ind. Aerodyn., 87, 203-216, 2000.

Van der Hoven, I.; Power Spectrum of Horizontal Wind Speed in the Frequency Range from 0.0007 to 900 Cycles per Hour, J. Meteor., 14, 160-164, 1957.

Von Karman, T.: Progress in the statistical theory of turbulence, Proc. Nat. Acad. Sci. 34, 530-539, 1948.

Wyngaard, J. C. and Coté, O. R.: The budgets of turbulent kinetic energy and temperature variance in the atmospheric surface layer, J. Atmos. Sci., 28, 190-201, 1971.

Zobeck, T. M.: Soil properties affecting wind erosion, J. Soil Water Cons., 46, 112-118, 1991. 